\title{
Folding Analysis of Hormonal Polypeptide \\ Calcitonins and the Oxidized Calcitonins \\ Using Electrospray Ionization Mass Spectrometry Combined with H/D Exchange
}

\author{
Yoshiaki Nabuchi* and Yoshinori Asoh \\ Fuji Gotemba Research Laboratories, Chugai Pharmaceutical Co., Ltd., Gotemba, Japan \\ Mitsuo Takayama \\ Graduate School of Integrated Science, Yokohama City University, Yokohama, Japan
}

\begin{abstract}
Conformational change of calcitonins has been examined by measuring the rate of hydrogen/ deuterium (H/D) exchange in amino acids. Time dependent $\mathrm{m} / \mathrm{z}$ shift caused by H/D exchange was monitored by electrospray ionization quadrupole ion trap mass spectrometry (ESI-QIT MS). The rate constants of H/D exchange were calculated from apparent first-order kinetics. The time course of H/D exchange exhibited two phases of faster and slower exchange. The smaller rate constant $\left(k_{2}\right)$ estimated from the slower H/D exchange was correlated with an $\alpha$-helix content that reflected the folding state. The order of $k_{2}$ values obtained for human calcitonin (hCT), porcine calcitonin $(\mathrm{pCT})$, salmon calcitonin $(\mathrm{sCT})$, and elcatonin $(\mathrm{ECT})$ was $\mathrm{hCT}>\mathrm{pCT} \approx \mathrm{sCT}>\mathrm{ECT}$. Although the amino acid sequence of $\mathrm{sCT}$ is similar to that of ECT, their $k_{2}$ values were considerably different. The results suggest that ECT is relatively rigid on the $\mathrm{N}$-terminal side cyclic structure in the folded state. Further, the effect of methionine oxidation on $k_{2}$ has been examined. In the oxidized pCT that possesses similar biological activity with the intact $\mathrm{pCT}$, the $k_{2}$ values obtained were nearly equal. The $k_{2}$ of hCT increased via methionine oxidation, and the biological activity was weakened by oxidation. This suggested that methionine oxidation of $\mathrm{hCT}$ produced unfolding in the secondary structure and that oxidative unfolding of hCT led to the loss of biological activity. The results indicate that the H/D exchange rate constant may be used as an informative parameter to elucidate the relationship between the folded state and biological activity of polypeptides like calcitonins with secondary structure. (J Am Soc Mass Spectrom 2004, 15, 1556-1564) (c) 2004 American Society for Mass Spectrometry
\end{abstract}

\begin{abstract}
C alcitonins (CTs) are calcium regulating hormones that inhibit osteoclastic bone resorption and induce calcium uptake from body fluids. By this biological action, CTs are used as potent drugs for various diseases such as Paget's disease, hypercalcemia, and osteoporosis. CTs are polypeptides consisting of 32 amino acids with a disulfide bond between Cys1 and Cys7 and a C-terminal proline amide (Figure 1). The polypeptide is produced by the parafollicular cells of the thyroid gland in mammals and by the ultimobranchial gland of fish [1]. Elcatonin (ECT) is a synthetic analogue of eel calcitonin that differs from the natural peptide hormone by replacement of the disulfide bond with an ethylene bond and deletion of the N-terminal amino group (Figure 1) [2]. In
\end{abstract}

Published online September 16, 2004

Address reprint requests to Y. Nabuchi, CMC Planning and Coordinating Dept., Chugai Pharmaceutical Co., Ltd., 5-5-1 Ukima, Kita-ku, Tokyo 115-8543, Japan. E-mail: nabuchiysa@chugai-pharm.co.jp

* Current address: Same as above. general, ultimobranchial CTs are more potent than thyroidal CTs in their hypocalcemic effect. The physiology and pharmacology of CTs have been reviewed by Azria [3].

The conformational structure of CT was studied by means of circular dichroism (CD) and nuclear magnetic resonance, and some attempts to find a relationship between the conformation and its hypocalcemic activity have been made. CTs have little ordered secondary structure in water; CTs in particular choose $\alpha$-helix in aqueous 2,2,2-trifluoroethanol (TFE) which is a structure-promoting solvent, or in sodium dodecyl sulfate (SDS) which mimics the membrane environment. The ordered structure is constructed from three conformational domains, the N-terminal side cyclic structure originating from the disulfide bond, a central $\alpha$-helix, and a flexible C-terminal region. The ability to form $\alpha$-helix in the presence of TFE has been reported to be $\mathrm{ECT}>$ salmonCT $(\mathrm{sCT})>$ porcine $\mathrm{CT}(\mathrm{pCT})>$ human CT (hCT) [4-7]. The presence of the $\alpha$-helix in the central region of CTs has been reported to be important 
$1 \quad 10 \quad 20 \quad 30$

hCT CGNLS T CML G T Y TQDF NKF H T F P Q T A I G V G A P $-\mathrm{NH}_{2}$

pCT C S NLS T C VLS A Y TR N L N N H R F S GMG F G P E T P - $\mathrm{NH}_{2}$

SCT C S NLS T C VLGKL S Q E L HKL Q T Y P R T N T G S G T P - $\mathrm{NH}_{2}$

ECT $\mathrm{CH}_{2} \mathrm{CO}-\mathrm{S}$ N L S T X V L GKL S Q E L HKL Q T Y P R T D V G A G T P $-\mathrm{NH}_{2}$

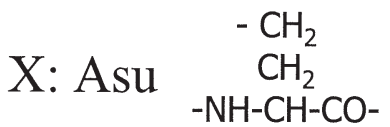

Figure 1. Primary structures of calcitonin and its analogue from various species. Underlined residues are reported to be formed $\alpha$-helix $[5,18,19]$.

for the interaction with membrane lipids and for hypocalcemic activity [8]. Using SDS solution, the difference of $\alpha$-helix content among species has correlated with the activity [4], and another report has suggested that conformational flexibility is also an important parameter for the activity [9]. Further, it has been reported that the biological activity of hCT was reduced via methionine oxidation, but no remarkable activity change was observed in pCT [10]. The molecular structure aspects of CT activity are not yet completely understood and are still a matter of controversy. It is expected, therefore, that a comprehensive study including kinetic elucidation of $\mathrm{CT}$ conformation will lead to understanding the relation between conformation and activity, as well as the inter-species difference of the activity. For this purpose, a method indicating whole peptide conformation is considered to be preferable.

Here we propose a mass spectrometric method to analyze folding of CTs, by estimating the rate of hydrogen/deuterium (H/D) exchange. In this method, a sample is incubated with a solvent containing deuterium and the time dependent $\mathrm{m} / \mathrm{z}$ shift by $\mathrm{H} / \mathrm{D}$ exchange is measured. The rate of $\mathrm{H} / \mathrm{D}$ exchange of active hydrogen in the amino acid side chains is faster than that of amide hydrogen on the peptide backbone [11]. Thus, the difference in the rate of H/D exchange of amide hydrogens is used for folding analysis coupled to electrospray ionization mass spectrometry (ESI MS). While there are many applications of $\mathrm{H} / \mathrm{D}$ exchange in protein conformational studies, there are few reports for peptides because the rate of $H / D$ exchange in peptides is much faster than that in protein under neutral $\mathrm{pH}$ conditions [12-15]. In this study, we measured the rate of $\mathrm{H} / \mathrm{D}$ exchange of hCT under several chemical conditions using ESI MS, and a correlation between the rate constant and the $\alpha$-helix content was estimated. The H/D exchange rates of hCT, sCT, pCT, and ECT were measured and compared with the order of known biological activity [3]. Further, the rate of $\mathrm{H} / \mathrm{D}$ exchange in intact calcitonins $\mathrm{hCT}$ and $\mathrm{pCT}$ and the methionine oxidized peptides $\operatorname{Met}(\mathrm{O}) \mathrm{hCT}$ and $\operatorname{Met}(\mathrm{O}) \mathrm{pCT}$ were measured to obtain the influence of oxidation on the folding state and activity.

\section{Experimental}

\section{Materials}

Calcitonins hCT and ECT were purchased from Peptide Institute, Inc. (Osaka, Japan) and American Peptide Company, Inc. (Sunnyvale, CA), respectively. pCT and $\mathrm{sCT}$ were obtained from Sigma (St. Louis, MO). Deuterium oxide $\left(\mathrm{D}_{2} \mathrm{O}\right)$, 2,2,2-trifluoroethanol-d3 (d3-TFE) and 2,2,2-trifluoroethanol (TFE) were purchased from Aldrich Chem. Co. (Milwaukee, WI), ISOTEC Inc. (Miamisburg, $\mathrm{OH}$ ), and Tokyo Chemical Industry (Tokyo, Japan), respectively. All other reagents used were of guaranteed high quality.

\section{Oxidative Preparation of $h C T$ and $p C T$}

One hundred $\mu \mathrm{L}$ of hCT (100 pmol/ $\mu \mathrm{L})$ solution was added to $400 \mu \mathrm{L}$ of $1 \%$ (vol/vol) formic acid. Then $5 \mu \mathrm{L}$ of $10 \%$ ( $\mathrm{vol} / \mathrm{vol}$ ) hydrogen peroxide was added and incubated for $60 \mathrm{~min}$ at $30^{\circ} \mathrm{C}$. After vacuum evaporation, $100 \mu \mathrm{L}$ of deionized water was added and stored at $-20{ }^{\circ} \mathrm{C}$ until $\mathrm{H} / \mathrm{D}$ exchange was performed. In the same manner, $\mathrm{pCT}$ was oxidized. The oxidized position of the products was confirmed by ESI MS of the peptide fragments obtained from trypsin digestion and cyano- 


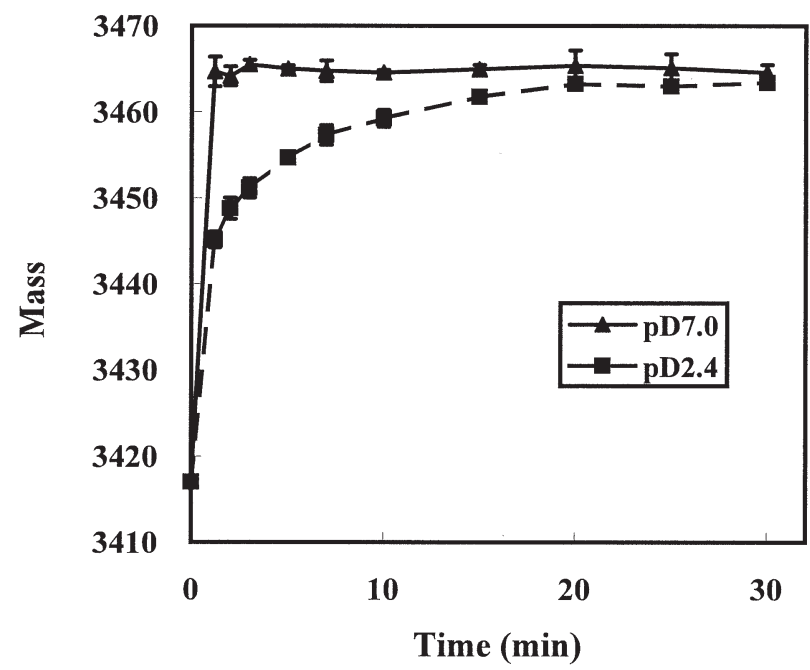

Figure 2. Time dependent mass shift of hCT by H/D exchange in neutral and acidic conditions. The measurements were carried out in $10 \mathrm{mM}$ ammonium acetate ( $\mathrm{pD} 7.0$ ) or $0.2 \%$ (vol/vol) formic acid (pD 2.4).

gen bromide (CNBr) cleavage. For trypsin digestion, the sample (approximately $500 \mathrm{pmol}$ ) was incubated with $1 / 100$ molar TPCK-trypsin at $37{ }^{\circ} \mathrm{C}$ for $6 \mathrm{~h}$ in $1 \%$ (wt/vol) ammonium hydrogen carbonate $(\mathrm{pH} 7.8)$. Then, an equi-volume of acetonitrile containing $2 \%$ (vol/vol) formic acid was added to terminate the digestion and the mixture was subjected to MS analysis. In the $\mathrm{CNBr}$ cleavage, the sample (approximately 500 pmol) was mixed with $225 \mu \mathrm{g}$ of $\mathrm{CNBr}$ in $1 \%$ (vol/vol) formic acid. After $18 \mathrm{~h}$ incubation at ambient temperature, an equi-volume of acetonitrile containing $2 \%$ (vol/ vol) formic acid was added and applied to MS analysis. Both samples were introduced into the mass spectrometer via direct infusion at a rate of $2 \mu \mathrm{l} / \mathrm{min}$.

\section{H/D Exchange Reaction}

Under aqueous conditions, $10 \mu \mathrm{L}$ of $\mathrm{CT}$ from each species (approximately $50 \mathrm{pmol} / \mu \mathrm{L}$ ) and $90 \mu \mathrm{L}$ of $\mathrm{D}_{2} \mathrm{O}$ containing $10 \mathrm{mmol} / \mathrm{L}$ ammonium acetate $(\mathrm{pD} 7.0)$ or $0.2 \%$ (vol/vol) formic acid (pD 2.4) was mixed to start the reaction. The $\mathrm{pD}$ was measured with a $\mathrm{HM}-30 \mathrm{~V} \mathrm{pH}$ meter equipped with a GST-5421C glass electrode (TOA electrochemical, Tokyo, Japan) previously calibrated with aqueous solutions. No attempt was made to cor-

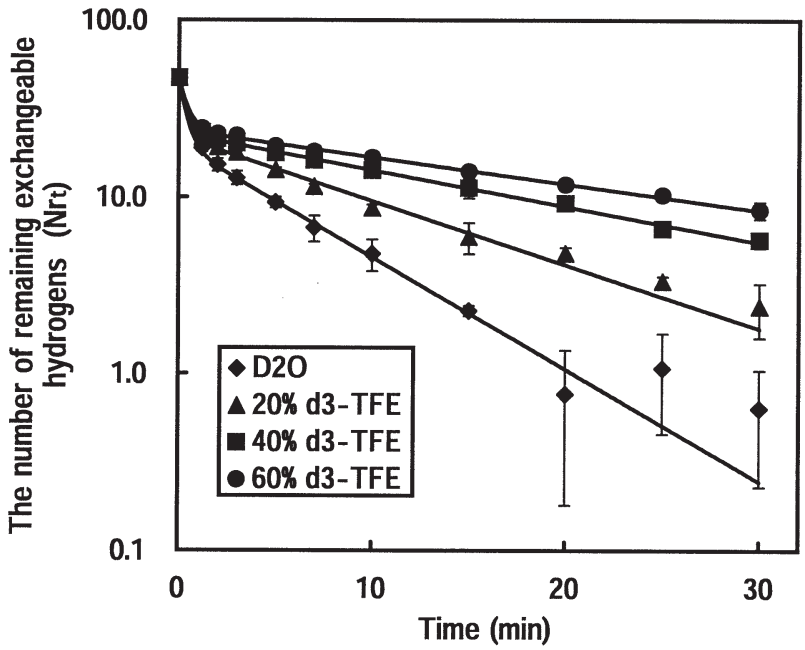

Figure 3. Time course in the number of remaining exchangeable hydrogens $\left(\mathrm{Nr}_{\mathrm{t}}\right)$ in $\mathrm{hCT}$ at different TFE concentrations. The measurements were initiated by mixing with deuterium oxide containing $0.2 \%$ formic acid and various concentrations of $\mathrm{d} 3$-TFE. The symbols are the mean \pm S.D. of measured values, and the solid lines are the best fits to eq 2. The time course of $\mathrm{H} / \mathrm{D}$ exchange involves all exchangeable hydrogen $\left(\mathrm{Nr}_{t}=\mathrm{N}_{\max }-\mathrm{N}_{\mathrm{t}}\right)$.

rect for differences in $\mathrm{H}_{2} \mathrm{O}$ and $\mathrm{D}_{2} \mathrm{O}$. In the presence of TFE, $5 \mu \mathrm{L}$ of $\mathrm{CT}$ (approximately $100 \mathrm{pmol} / \mu \mathrm{L}$ ) was mixed with $5 \mu \mathrm{L}$ of TFE $/ \mathrm{H}_{2} \mathrm{O}(40$ or $80 \%(\mathrm{vol} / \mathrm{vol}))$ or $7.5 \mu \mathrm{L}$ of TFE and kept for 5 min at ambient temperature. Subsequently, $90 \mu \mathrm{L}$ of $\mathrm{d} 3-\mathrm{TFE} / \mathrm{D}_{2} \mathrm{O}$ containing $0.2 \%$ (vol/vol) formic acid was added to start the reaction. The final concentrations of d3-TFE used were 20,40 , and $60 \%$ (vol/vol). The reaction mixture filled in a micro-syringe was kept at an ambient temperature during H/D exchange. Time dependent $m / z$ shift of CT in each species was observed mass spectrum from a direct infusion syringe pump equipped instrument.

\section{Mass Spectrometry}

Mass spectra were obtained with an LCQ DECA quadrupole ion trap mass spectrometer (QIT MS) equipped with an electrospray ion source and Xcalibur data processor (Thermoquest, Tokyo, Japan). A capillary temperature of $30^{\circ} \mathrm{C}$, along with a spray voltage of 5 $\mathrm{kV}$, and nitrogen as the sheath gas were employed for the measurement of H/D content. A solution of CT from each species was used for setting the instrument

Table 1. Apparent first order rate constants of $\mathrm{H} / \mathrm{D}$ exchange in $\mathrm{hCT}$ under various TFE concentrations

\begin{tabular}{lcccc}
\hline & \multicolumn{4}{c}{ TFE concentration } \\
\cline { 2 - 5 } & $0 \%$ & $20 \%$ & $40 \%$ & $60 \%$ \\
\hline \hline $\mathrm{A}$ & $27.4 \pm 2.2$ & $25.2 \pm 1.0$ & $24.2 \pm 0.6$ & $23.3 \pm 1.4$ \\
$\mathrm{~B}$ & $19.6 \pm 2.2$ & $21.8 \pm 1.0$ & $22.8 \pm 0.6$ & $23.7 \pm 1.4$ \\
$k_{1}\left(\mathrm{~min}^{-1}\right)$ & $2.44 \pm 1.08$ & $2.84 \pm 1.72$ & $2.32 \pm 0.40$ & $2.14 \pm 0.26$ \\
$k_{2}\left(\min ^{-1}\right)$ & $0.1461 \pm 0.0043$ & $0.0834 \pm 0.0046$ & $0.0474 \pm 0.0014$ & $0.0348 \pm 0.0031$ \\
\hline
\end{tabular}

Each value represents mean \pm S.D. of three experiments. A and B are coefficients for the kinetic model equation, eq. 2 . 


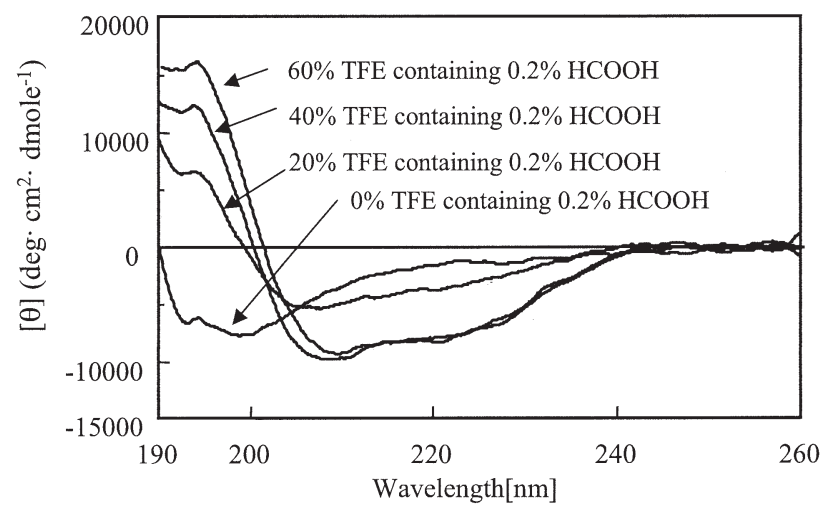

Figure 4. Influence of TFE concentration on circular dichroism pattern of hCT.

parameters including sheath gas flow rate, and the automatic and semi-automatic tuning methods of Xcalibur. The rate of direct infusion of the sample solution was $2 \mu \mathrm{L} / \mathrm{min}$ during all MS measurements. For the $\mathrm{H} / \mathrm{D}$ content, the $\mathrm{m} / \mathrm{z}$ value of molecular-related ions of the sample at each sampling time was obtained from the deconvoluted spectrum acquired for $0.2 \mathrm{~min}$ from each sampling time. To save the sample amount, sample infusion into mass spectrometer was performed each $0.5 \mathrm{~min}$ before and after each sampling time. It was confirmed that mass spectra measured using the above method were similar to mass spectra measured under continuous infusion.

\section{Circular Dichroism Spectroscopy}

Circular dichroism (CD) spectra were obtained with a Jasco J-725 spectrometer equipped with a J-700 data processor (JASCO, Tokyo, Japan). The spectra were measured between 190 and $260 \mathrm{~nm}$ at ambient temperature. The measurement was carried out with $\mathrm{CT}$ concentration of $10 \mathrm{nmol} / \mathrm{mL}$ in TFE $/ \mathrm{H}_{2} \mathrm{O}[0,20,40$, and $60 \%$ of TFE (vol/vol)] containing $0.2 \%$ formic acid. Percent content of $\alpha$-helix in the CT peptide was calculated by following the equation [16].

$$
\% \alpha-\text { helix }=\left([\theta]_{208 \mathrm{~nm}}-4000\right) /(33000-4000)
$$

\section{Estimation of H/D Exchange Rate Constants}

The maximum number of hydrogen exchangeable to deuterium, $\mathrm{N}_{\max }$, was calculated from the observed

Table 2. $\alpha$-helix content of hCT calculated from circular dichroism spectra under various TFE concentrations

\begin{tabular}{ccc}
\multicolumn{3}{c}{ dichroism spectra under various TFE concentrations } \\
\hline $\begin{array}{c}\text { TFE } \\
\text { concentration (\%) }\end{array}$ & {$[\theta] 208 \mathrm{~nm}$} & $\alpha$-Helix content (\%) \\
\hline \hline 0 & -4188.2 & 0.6 \\
20 & -5446.6 & 5.0 \\
40 & -9877.4 & 20.3 \\
60 & -9132.1 & 17.7
\end{tabular}

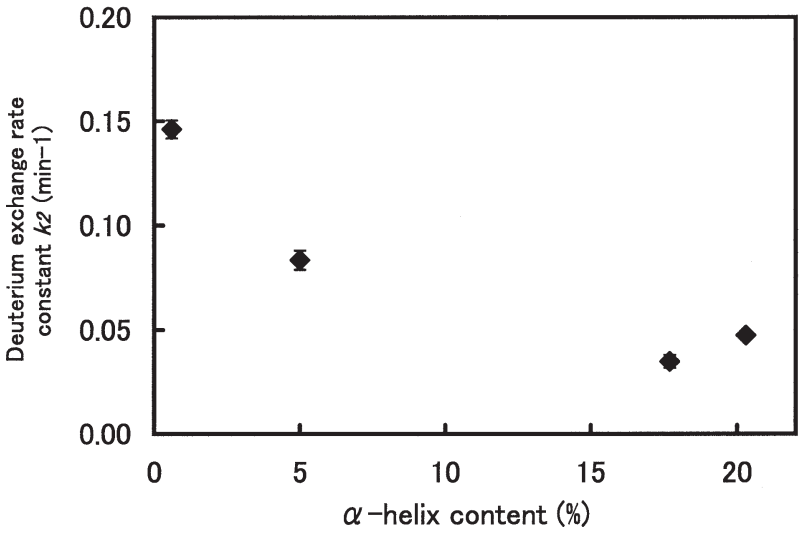

Figure 5. Correlation between $\alpha$-helix content and H/D exchange rate constant $k_{2}$ of hCT.

mass difference between intact and fully deuterated peptide (after 2 to $4 \mathrm{~h}$ incubation). During $30 \mathrm{~min}$ incubation with deuterated solvent, the deconvoluted mass of a sample was observed and the number of exchanged hydrogen atoms at each sampling time $\left(\mathrm{N}_{\mathrm{t}}\right)$ was calculated. The measurement was performed three times for each CT. The number of remaining exchangeable hydrogen atoms, $\mathrm{Nr}_{\mathrm{t}}$, was obtained by subtracting $\mathrm{N}_{\mathrm{t}}$ from $\mathrm{N}_{\max }$, that is, $\mathrm{Nr}_{\mathrm{t}}=\mathrm{N}_{\max }-\mathrm{N}_{\mathrm{t}}$. To estimate $\mathrm{H} / \mathrm{D}$ exchange rate constants, apparent first-order kinetic model (eq 2) was used. From a time course plot of $\mathrm{Nr}_{\mathrm{t}}$, the rate constants, $k_{1}$ and $k_{2}$, were estimated by a non-linear least-squares regression analysis using WinNonlin version 2.1 (Scientific Consulting, Inc., Apex, $\mathrm{NC})$. Though effect of back-exchange was not measured in this study, H/D exchange was conducted under the same ratio of deuterized solvents. Thus, comparison of each result with folded states of each peptide would be possible. The calculated rate constants between differ-

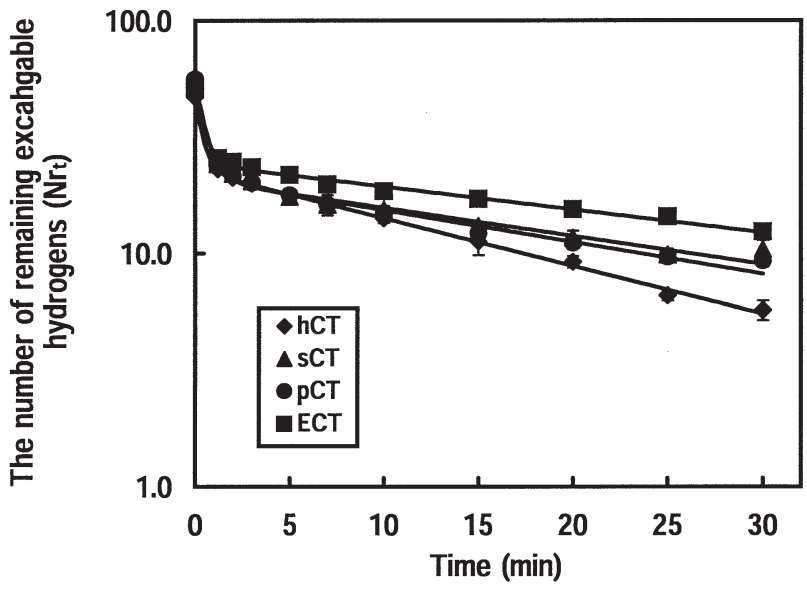

Figure 6. Time course in the number of remaining exchangeable hydrogens $\left(\mathrm{Nr}_{\mathrm{t}}\right)$ in CTs. The measurements were initiated by mixing with deuterium oxide containing $0.2 \%$ formic acid and $40 \%$ d3-TFE. The symbols are the mean \pm S.D. of measured values, and the solid lines are the best fits to eq 2 . The time course of $\mathrm{H} / \mathrm{D}$ exchange involves all exchangeable hydrogen $\left(\mathrm{Nr}_{\mathrm{t}}=\mathrm{N}_{\max }-\mathrm{N}_{\mathrm{t}}\right)$. 
Table 3. Apparent first order rate constants of H/D exchange in CTs

\begin{tabular}{lcccc}
\hline & hCT & sCT & pCT & ECT \\
\hline \hline A & $24.2 \pm 0.6$ & $35.1 \pm 0.9$ & $34.9 \pm 0.5$ & $26.6 \pm 0.7$ \\
B & $22.8 \pm 0.6$ & $20.8 \pm 0.9$ & $21.0 \pm 0.5$ & $24.4 \pm 0.7$ \\
$k_{1}\left(\min ^{-1}\right)$ & $2.32 \pm 0.40$ & $1.69 \pm 0.18$ & $1.74 \pm 0.11$ & $2.04 \pm 0.25$ \\
$k_{2}\left(\min ^{-1}\right)$ & $0.0474 \pm 0.0014 \dagger^{\# \$}$ & $0.0280 \pm 0.0021^{*}$ & $0.0316 \pm 0.0010^{* \$}$ & $0.0228 \pm 0.0029^{* \#}$ \\
\hline
\end{tabular}

Each value represents mean \pm S.D. of three experiments. $A$ and $B$ are coefficients for the kinetic model equation, eq. 2 .

${ }^{*}: P<.05$ vs. hCT, †: $P<.05$ vs. sCT, \#: $P<.05$ vs. pCT, $\$: P<.05$ vs. ECT

ent species CTs were compared with each other using the Student t-test or Tukey test. Statistical significance was defined as $P<.05$.

$$
\mathrm{Nr}_{\mathrm{t}}=\mathrm{Ae}^{-\mathrm{k} 1 \mathrm{t}}+\mathrm{Be}^{-\mathrm{k} 2 \mathrm{t}} \quad\left(k_{1}>k_{2}\right)
$$

[A and B: coefficients]

\section{Results and Discussion}

\section{Effect of $p D$ on $H / D$ Exchange Rate in $h C T$}

The time dependent $\mathrm{m} / \mathrm{z}$ shift of hCT by H/D exchange in $10 \mathrm{mM}$ ammonium acetate (pD 7.0) or $0.2 \%$ (vol/vol) formic acid ( $\mathrm{pD}$ 2.4) was measured (Figure 2). Using $10 \mathrm{mM}$ ammonium acetate, it was observed that the exchange of $47.4 \pm 1.72$ hydrogen atoms to deuterium occurred within $1.2 \mathrm{~min}$ i.e., at the first sampling point, subsequent $m / z$ change was not observed. The deconvoluted mass of hCT observed at this time was $3464.7 \pm$ $1.72 \mathrm{u}$. Using $0.2 \%$ ( $\mathrm{vol} / \mathrm{vol}$ ) formic acid, on the other hand, resulted in time dependent $\mathrm{m} / \mathrm{z}$ shift by $\mathrm{H} / \mathrm{D}$ exchange with a slower rate than that at $\mathrm{pD}$ 7.0. The deconvoluted mass observed after $30 \mathrm{~min}$ incubation was $3463.4 \pm 0.40 \mathrm{u}$. This corresponded to a change of $46.4 \pm 0.40$ hydrogens. Under neutral pD condition, which is often applied for protein studies, the H/D exchange rate of hCT was too fast to measure. This suggests that hCT does not have a rigid conformation in aqueous solution. It has been known, in fact, that the $\mathrm{H} / \mathrm{D}$ exchange rate of amide hydrogen becomes slower under acidic conditions [11, 17]. Thus, the acidic pD condition with $0.2 \%$ (vol/vol) formic acid was employed in this study.

\section{Relationship of H/D Exchange Rate to $\alpha$-Helix Content in $h \mathrm{CT}$}

The $m / z$ change of hCT by H/D exchange was measured in the presence of the structure-promoting solvent TFE $[0,20,40$, and $60 \%$ (vol/vol)]. Time courses of the number of remaining exchangeable hydrogen atoms, $\mathrm{Nr}_{\mathrm{t}}$, were plotted (Figure 3). The number of exchanged hydrogen atoms decreased with increasing TFE concentration. Each H/D exchange time course exhibited apparent first-order kinetics, and good curve fitting with the two-phase model equation was found. Though enough data points were not obtained in the faster phase, data points for the slower phase were sufficient to obtain an accurate rate constant. The calculated rate constants are shown in Table 1. The slower phase rate constant, $k_{2}$, was changed depending upon the TFE concentration, while the faster phase rate constant, $k_{1}$, was unchanged. As was already reported, it has been suggested [11] that the exchange of the amino acid side chain hydrogen is related to the faster phase of the reaction and the most of backbone amide hydrogen exchange is included in the slower phase. The values of coefficients $A$ and $B$ (eq 2) represent the number of hydrogen in each phase. The sum of $\mathrm{A}$ and $B$ is equal to the $\mathrm{H}_{\max }$.

The CD spectra of hCT under several TFE concentrations were measured and the $\alpha$-helix contents calculated (Figure 4 and Table 2). It was assumed that the calculated $\alpha$-helix contents of hCT have a nearly random coil conformation in water. With the addition of TFE, hCT appeared to assume a more ordered conformation and the CD curve showed characteristics of $\alpha$-helix formation with negative bands at 208 and 222 $\mathrm{nm}$. In this study, we employed pD2.4 for the measurement of $\mathrm{H} / \mathrm{D}$ exchange rate, and the condition differs from a $\mathrm{pH}$ in which $\mathrm{CT}$ exhibits a biological activity. Despite this acidic condition, formation of $\alpha$-helix was observed in hCT (Figure 4).

The $\alpha$-helix contents obviously increased with increasing TFE concentration. And, the increase in $\alpha$-helix content decreased $k_{2}$ (Figure 5). Thus, $k_{2}$ can be used as a marker of the folded state of the peptide. If an equation, which expresses exact relationship between $\alpha$-helix content and $k_{2}$, was obtained, $\alpha$-helix content could be estimated from $\mathrm{H} / \mathrm{D}$ exchange. In order to obtain the equation, further studies are required. Furthermore, the coefficient, B, tended to increase with the increase in TFE concentration (Table 1). This indicates that the number of hydrogen, which shows slower H/D exchange rate, increases with the formation of $\alpha$-helix. Therefore, the coefficient, B, could be considered as another marker for the folded state of the peptide. For the purpose to compare folded states of whole peptide molecules, the twophase model equation employed in this study can give sufficient information.

Same as hCT, $k_{2}$ is considered to be applicable as the marker of the folded state of other CTs. Because, CTs have similar amino acid sequences and $\mathrm{N}$-terminal cyclic structure (Figure 1), and the secondary structure is promoted by addition of TFE [4-6].

Compared with CD spectroscopy, the advantage of 
Table 4. Mass-to-charge ratios of tryptic peptides and CNBr cleaved products of oxidized hCT and pCT

\begin{tabular}{|c|c|c|c|c|c|}
\hline \multicolumn{6}{|c|}{ Tryptic digestion hCT } \\
\hline \multirow{4}{*}{$\begin{array}{c}\text { Peptde } \\
\mathrm{T} 1\end{array}$} & \multirow{4}{*}{$\begin{array}{l}\text { Position } \\
1-18\end{array}$} & & & \multicolumn{2}{|c|}{ Observed mass } \\
\hline & & \multicolumn{2}{|c|}{ Theoretical mass } & Intact & Oxidized \\
\hline & & {$[\mathrm{M}+\mathrm{H}]^{+}$} & 1993.9 & 1993.5 & \\
\hline & & {$[\mathrm{M}+2 \mathrm{H}]^{2+}$} & 997.4 & 997.8 & $1005.5^{\mathrm{a}}$ \\
\hline \multirow[t]{2}{*}{$\mathrm{T} 2$} & $19-32$ & {$[\mathrm{M}+\mathrm{H}]^{+}$} & 1441.8 & 1441.5 & 1441.5 \\
\hline & & {$[\mathrm{M}+2 \mathrm{H}]^{2+}$} & 721.4 & 721.3 & 721.3 \\
\hline \multicolumn{6}{|l|}{$\mathrm{pCT}$} \\
\hline \multirow[t]{2}{*}{ Peptde } & Position & \multicolumn{2}{|c|}{ Theoretical mass } & \multicolumn{2}{|c|}{ Observed mass } \\
\hline & & & & Intact & Oxidized \\
\hline \multirow[t]{2}{*}{$\mathrm{T} 1$} & $1-14$ & {$[\mathrm{M}+\mathrm{H}]^{+}$} & 1600.7 & 1600.5 & 1600.5 \\
\hline & & {$[\mathrm{M}+2 \mathrm{H}]^{2+}$} & 800.9 & 800.9 & 800.9 \\
\hline \multirow[t]{2}{*}{$\mathrm{T} 2$} & $15-21$ & {$[\mathrm{M}+\mathrm{H}]^{+}$} & 914.5 & 914.5 & 914.5 \\
\hline & & {$[\mathrm{M}+2 \mathrm{H}]^{2+}$} & 457.7 & 457.7 & 457.8 \\
\hline \multirow[t]{2}{*}{ T3 } & $22-32$ & {$[\mathrm{M}+\mathrm{H}]^{+}$} & 1125.5 & 1125.3 & $1141.3^{\mathrm{a}}$ \\
\hline & & {$[\mathrm{M}+2 \mathrm{H}]^{2+}$} & 563.3 & 563.3 & $571.2^{\mathrm{a}}$ \\
\hline \multicolumn{6}{|c|}{ CNBr cleavage hCT } \\
\hline \multirow[t]{2}{*}{ Peptde } & Position & \multicolumn{2}{|c|}{ Theoretical mass } & \multicolumn{2}{|c|}{ Observed mass } \\
\hline & & & & Intact & Oxidized \\
\hline $\mathrm{C} 1$ & $1-8$ & {$[\mathrm{M}+\mathrm{H}]^{+}$} & 778.3 & 778.3 & n.d. \\
\hline \multirow[t]{2}{*}{$\mathrm{C} 2$} & $9-32$ & {$[\mathrm{M}+2 \mathrm{H}]^{2+}$} & 1305.2 & 1305.6 & n.d. \\
\hline & & {$[\mathrm{M}+3 \mathrm{H}]^{3+}$} & 870.4 & 870.7 & n.d. \\
\hline \multicolumn{6}{|l|}{ pCT } \\
\hline \multirow[t]{2}{*}{ Peptde } & Position & \multicolumn{2}{|c|}{ Theoretical mass } & \multicolumn{2}{|c|}{ Observed mass } \\
\hline & & & & Intact & Oxidized \\
\hline \multirow[t]{2}{*}{$\mathrm{C} 1$} & $1-25$ & {$[\mathrm{M}+2 \mathrm{H}]^{2+}$} & 1435.7 & 1435.6 & n.d. \\
\hline & & {$[\mathrm{M}+3 \mathrm{H}]^{3+}$} & 957.4 & 957.9 & n.d. \\
\hline $\mathrm{C} 2$ & $26-32$ & {$[\mathrm{M}+\mathrm{H}]^{+}$} & 703.3 & 703.3 & n.d. \\
\hline
\end{tabular}

C1 was detected as homoserine lactone

aThe values have 16 mass increment against theoretical mass values.

ESI MS is that the amount of sample is less. Approximately a 10-fold smaller quantity was used for ESI MS in this study. It should be possible to reduce the sample amount further.

\section{H/D Exchange of CTs and CT Analogue}

Time dependent $m / z$ shift of hCT, sCT, pCT, and ECT resulting from $\mathrm{H} / \mathrm{D}$ exchange was measured in $40 \%$ (vol/vol) TFE containing $0.2 \%$ (vol/vol) formic acid. The time course plots of $\mathrm{Nr}_{\mathrm{t}}$ and the calculated rate constants are shown in Figure 6 and Table 3. The order of the slower exchange rate constant, $k_{2}$, was hCT $>$ $\mathrm{pCT} \approx \mathrm{sCT}>\mathrm{ECT}$. The observed difference in $k_{2}$ is interesting in connection with the relative ability to form an $\alpha$-helix in neutral $\mathrm{pH}$, which was obtained with CD study [4]. Therefore, it is suggested that the H/D exchange rate measured under acidic condition ( $\mathrm{pD}$ 2.4) reflects the secondary structure formed in neutral $\mathrm{pH}$. In fact, it has been reported that $\alpha$-helix formation is preserved at both acidic and neutral $\mathrm{pH}$ in $\mathrm{hCT}$ and $\mathrm{SCT}$
$[18,19]$. Although the amino acid sequence of sCT was similar to that of ECT, their rate constants, $k_{2}$, were different. This suggested that the modification in the $\mathrm{N}$-terminal side cyclic structure of ECT brought about a more rigid folded state.

On the other hand, the order of biological activity of $\mathrm{CT}$ s has been reported as $\mathrm{pCT} \leq \mathrm{hCT}<\mathrm{sCT} \approx \mathrm{ECT}$ [3]. The result obtained above indicates that an obvious relationship is not observed between $k_{2}$ and the biological activity. In particular, $\mathrm{pCT}$ and sCT had similar $k_{2}$ values, despite the large difference in biological activity [10]. This might indicates that the folded state of CT evaluated from $\mathrm{H} / \mathrm{D}$ exchange is not necessarily related to the biological activity. However, the TFE concentration used here, $40 \%$ (vol/vol), was a limiting condition that led CTs to fully folded states. This is supported by reports that in CTs, the $\mathrm{CD}$ patterns corresponding to $\alpha$-helix formation changed with TFE concentration and showed two phases $[4,6]$. That is, a considerable change in CD patterns was observed in the first phase at lower TFE concentration, while a minor change was observed 
in the second phase of the higher TFE concentration. The TFE concentration used here is classified as the second phase. It is still uncertain whether the fully folded state is the optimum conformation for binding to the CT receptor. Further kinetic studies, including H/D exchange under various TFE concentration conditions, are necessary to obtain a more firm relationship between the rate constant, $k_{2}$, and the biological activity.

As another possible method to obtain folded state of the peptides, use of membrane mimetic agents would be proposed. Some surfactants such as SDS and phospholipids could be used as membrane mimetic agents. Secondary structure obtained by the agents might be more comparable to a conformation for binding to the CT receptor. However, ionization of peptides by ESI would be disturbed by surfactant which could be used as the membrane mimetic agents. Thus, another mild ionization method such as MALDI might be useful for the mass measurement of such samples. To employ MALDI for this purpose, appropriate methods to prevent progress of $H / D$ exchange during a sample preparation for MALDI should be necessary to obtain valuable mass spectra for kinetic analysis.

\section{Methionine Oxidation of $h C T$ and $p C T$}

Oxidized products of hCT and pCT were analyzed by ESI MS and the amino acid residue oxidized under the conditions of $0.1 \%$ (vol/vol) $\mathrm{H}_{2} \mathrm{O}_{2}$ for $60 \mathrm{~min}$ was confirmed by the mass change in the tryptic peptide and $\mathrm{CNBr}$ cleavage fragment. Mass spectra of intact hCT and oxidized hCT showed peaks due to a doublyprotonated molecule $[\mathrm{M}+2 \mathrm{H}]^{2+}$ at $\mathrm{m} / z 1709.5$ and 1717.5, respectively. An observed $m / z$ difference, 8 Da, indicated the introduction of one oxygen atom via oxidation. On the other hand, oxidized pCT showed doubly- and triply-protonated molecules, $[\mathrm{M}+2 \mathrm{H}]^{2+}$ at $m / z 1810.1$ and $[\mathrm{M}+3 \mathrm{H}]^{3+}$ at $m / z 1207.2$, in the ESI mass spectrum. Similarly, the $\mathrm{m} / \mathrm{z}$ differences from intact pCT suggested that one oxygen atom was introduced via oxidation.

To determine the oxidized position in hCT (CGNLSTCMLGTYTQDFNKFHTFPQTAIGVGAP-NH $\left.{ }_{2}, 1-32\right)$, intact and oxidized hCT were treated with trypsin or $\mathrm{CNBr}$, and the products were analyzed by ESI MS. In the tryptic digest of oxidized hCT, an increment of $8 \mathrm{Da}$ in $m / z$ value from intact hCT was observed in the $[\mathrm{M}+$ $2 \mathrm{H}]^{2+}$ ion of a peptide fragment $1-18$, whereas no $\mathrm{m} / \mathrm{z}$ change was observed in the peptide fragment corresponding to 19-32 (Table 4). This suggested that oxidation occurred at an amino acid residue in 1-18. The intact hCT was also cleaved at the C-terminal side amide bond of Met8, with CNBr. However, cleavage at this position did not occur in the oxidized hCT (Table $4)$. These results indicate that Met8 was oxidized and that the methionine oxidized tryptic peptide $\operatorname{Met}(\mathrm{O}) \mathrm{h}$ CT was produced. The same analysis performed on pCT revealed that the oxidation occurred at Met25 and

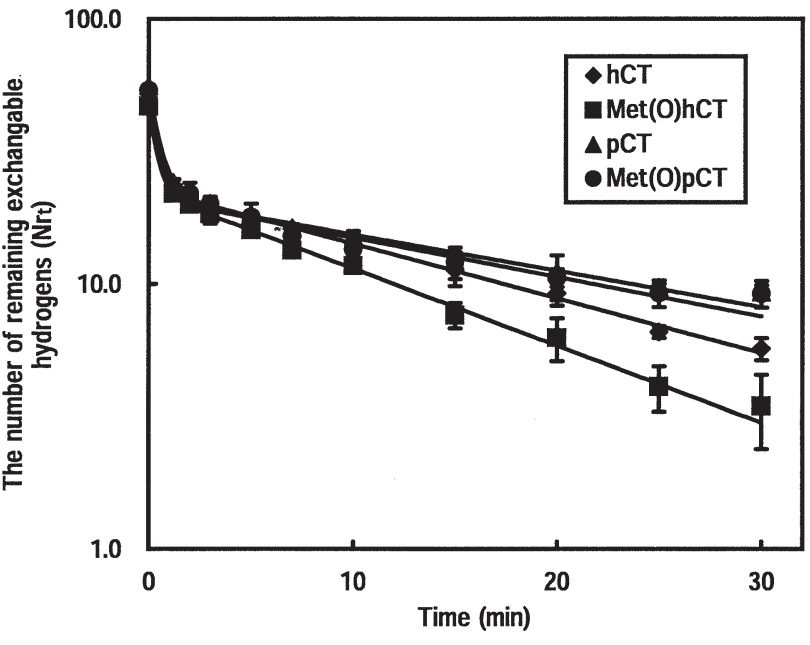

Figure 7. Time course in the number of remaining exchangeable hydrogens $\left(\mathrm{Nr}_{\mathrm{t}}\right)$ in intact and methionine oxidized CTs. The measurements were initiated by mixing with deuterium oxide containing $0.2 \%$ formic acid and $40 \%$ d3-TFE. The symbols are the mean \pm S.D. of measured values, and the solid lines are the best fits to eq 2. The time course of $H / D$ exchange involves all exchangeable hydrogen $\left(\mathrm{Nr}_{\mathrm{t}}=\mathrm{N}_{\max }-\mathrm{N}_{\mathrm{t}}\right)$.

that the oxidized tryptic peptide $\mathrm{Met}(\mathrm{O}) \mathrm{pCT}$ formed. Other amino acid residues were not oxidized. The results obtained with tryptic digestion or $\mathrm{CNBr}$ cleavage are summarized in Table 4.

\section{Influence of Methionine Oxidation of CTs on $H / D$ Exchange and Folded State}

The time dependent $m / z$ shift of hCT, Met(O)hCT, $\mathrm{pCT}$, and $\operatorname{Met}(\mathrm{O}) \mathrm{pCT}$ by $\mathrm{H} / \mathrm{D}$ exchange was measured in $40 \%$ (vol/vol) TFE containing $0.2 \%$ (vol/vol) formic acid. Methionine oxide is one of the possible degradation products in peptides and proteins. The time course plots of $\mathrm{Nr}_{\mathrm{t}}$ and rate constants $k_{1}$ and $k_{2}$ are shown in Figure 7 and Table 5. The H/D exchange rate constant, $k 1$, did not change with methionine oxidation for either CT. The rate constant, $k_{2}$, of pCT was also unchanged with oxidation. These results suggest that in $\mathrm{pCT}$, the considerable change of conformation did not occur by methionine oxidation. In fact, $\mathrm{Met}(\mathrm{O}) \mathrm{pCT}$ possesses similar biological activity to that of intact pCT [10].

On the other hand, methionine oxidation of hCT resulted in a significant increase in rate constant, $k_{2}$. The oxidation of hCT also reduces biological activity [10]. This indicates that in hCT unfolding occurs by methionine oxidation and oxidation leads to the loss of the biological activity. CT consists of three structural parts: the N-terminal side ring structure region between amino acid position at 1 to 7 , an $\alpha$-helix region, and the remaining $\mathrm{C}$-terminal side flexible region $[5,7]$. It has been known that entire structural regions are necessary for full biological activity [20]. Any effect of methionine oxidation on folding state of 
Table 5. Apparent first order rate constants of H/D exchange in intact and methionine oxidized CTs

\begin{tabular}{lccr}
\hline & hCT & Met(O)hCT & Met(O)pCT \\
\hline \hline A & $24.2 \pm 0.6$ & $24.8 \pm 0.6$ & $34.9 \pm 0.5$ \\
B & $22.8 \pm 0.6$ & $22.2 \pm 0.6$ & $21.0 \pm 0.5$ \\
$k_{1}\left(\min ^{-1}\right)$ & $2.32 \pm 0.40$ & $2.39 \pm 0.45$ & $1.74 \pm 0.11$ \\
$k_{2}\left(\min ^{-1}\right)$ & $0.0474 \pm 0.0014$ & $0.0667 \pm 0.0068^{*}$ & $0.0316 \pm 0.0010$ \\
\hline
\end{tabular}

Each value represents mean \pm S.D. of three experiments. $A$ and $B$ are coefficients for the kinetic model equation, eq 2 .

*: $P<.05$ against intact peptide.

pCT was undetectable in this study. This can be rationalized in that Met25 of pCT exists in the Cterminal side flexible region. On the other hand, Met8 of hCT exists in the intermediate region between the $\mathrm{N}$-terminal side and the $\alpha$-helix, which would contribute to form a rigid conformation of the peptide. Therefore, the increase in the rate constant $k_{2}$ and the loss of biological activity via oxidation can be successfully explained on the basis that methionine oxidation leads to unfolding of the intermediate region.

\section{Conclusions}

This study has demonstrated that ESI MS combined with $H / D$ exchange is a powerful tool to analyze the folded states of polypeptides like CTs, and that the method would be applicable for modified peptides such as artificially mutated peptides and degraded products. The H/D exchange kinetic data for hormonal polypeptide CTs can be correlated with the folded state as estimated from the $\alpha$-helix content by CD spectroscopy and their biological activity. It is obvious that the folded states involving secondary structural features of polypeptides can be monitored by ESI MS. The slower rate constant, $k_{2}$, estimated by ESI MS can be used as an informative marker for the folded state of peptides. Further, the influence of methionine oxidation in pCT and hCT on the rate constant, $k_{2}$, could be correlated with the biological activity of the peptide. It was suggested that inactivation of hCT via methionine oxidation was caused by unfolding of the secondary structure of the hCT peptide. The H/D exchange method with ESI MS analysis was sensitive enough to detect the folded state due to even one amino acid modification. A comparison of the slower rate constant, $k_{2}$, of the oxidized peptide with that of unoxidized peptide made it possible for us to discuss the biological activity and its change. Consequently, the rate constant $k_{2}$ will become a useful parameter to elucidate the relationship between the folded states and biological activity of polypeptides.

\section{References}

1. Austin, L. A.; Heath, H. Calcitonin. New. Engl. J. Med. 1981, $304,269-278$.
2. Morikawa, T.; Munekata, E.; Sakakibara, S.; Noda, T.; Otani, M. Synthesis of Eel-Calcitonin and [ASU1,7]-Eel-Calcitonin: Contribution of the Disulfide Bond to the Hormonal Activity. Experientia 1976, 32, 1104-1106.

3. Azria, M. The Calcitonins: Physiology and Pharmacology; Karger: Basel, Switzerland: 1989; pp 4-19.

4. Siligardi,; G. Samorí,; B. Melandri,; S. Visconti,; M. Drake,; A. F. Correlation Between Biological Activities and Conformational Properties for Human, Salmon, Eel, Porcine Calcitonins and Elcatonin Elucidated by CD Spectroscopy. Eur. J. Biochem. 1994, 221, 1117-1125

5. Ogawa, K.; Nishimura, S.; Doi, M.; Kyogoku, Y.; Hayashi, M.; Kobayashi, Y. Conformational Analysis of Elcatonin in Solution. Eur. J. Biochem. 1994, 222, 659-666

6. Arvinte, T.; Drake, A. F. Comparative Study of Human and Salmon Calcitonin Secondary Structure in Solutions with Low Dielectric Constants. J. Biol. Chem. 1993, 268, 6408-6414.

7. Amodeo, P.; Motta, A.; Strazzullo, G; Moewlli, M. A. C. Conformational Flexibility in Calcitonin: The Dynamic Properties of Human and Salmon Calcitonin in Solution. J. Biomol. NMR 1999, 13, 161-174.

8. Epand, R. M.; Epand, R. F.; Orlowski, R. C.; Schlueter, R. J.; Boni L. T.; Hui, S. W. Amphipathic Helix and Its Relationship to the Interaction of Calcitonin with Phospholipids. Biochemistry 1983, 22, 5074-5084.

9. Epand, R. M.; Epand, R. F. Conformational Flexibility and Biological Activity of Salmon Calcitonin. Biochemistry 1986, 25, 1964-1968.

10. Guttmann, S. T. Chemistry and Structure-Activity Relationship of Natural and Synthetic Calcitonins. In Calcitonin: Therapeutisch Potential Osteoporose, Fed. Rep. Ger: Stuttgart, 1984; pp 63-74.

11. Wüthrich, K.; Wagner, G. Nuclear Magnetic Resonance of Labile Protons in the Basic Pancreastic Trypsin Inhibitor. J. Mol. Biol. 1979, 130, 1-18.

12. Zhang, Z.; Smith, D. L. Determination of Amide Hydrogen Exchange by Mass Spectrometry: A New Tool for Protein Structure Elucidation. Protein Sci. 1993, 2, 522-531.

13. Robinson, C. V.; Groß, M.; Eyles, S. J.; Ewbank, J. J.; Mayhew, M.; Hartl, F. U.; Dobson C. M.; Radford, S. E. Conformation of GroEL-Bound $\alpha$-Lactalbumin Probed by Mass Spectrometry. Nature 1994, 372, 646-651.

14. Akashi, S.; Naito, Y.; Takio, K. Observation of Hydrogen/ Deuterium Exchange of Ubiquitin by Direct Analysis of Electrospray Capillary-Skimmer Dissociation with Fourier Transform Ion Cyclotron Resonance Mass Spectrometry. Anal. Chem. 71, 1999, 4974-4980.

15. Wagner, D. S.; Melton, L. G.; Yan, Y.; Erickson, B. W.; Anderegg, R. J. Deuterium Exchange of $\alpha$-Helices and $\beta$-Sheets as Monitored by Electrospray Ionization Mass Spectrometry. Protein Sci. 1994, 3, 1305-1314.

16. Greenfield, N.; Fasman, G. D. Computed Circular Dichroism Spectra for the Evaluation of Protein Conformation. Biochemistry 1969, 8, 4108-4116. 
17. Bai, Y.; Milne, J. S.; Mayne, L.; Englander, S. W. Primary Structure Effects of Peptide Group Hydrogen Exchange. Proteins 1993, 17, 75-86.

18. Motta, A.; Andreotti, G.; Amodeo, P.; Strazzullo, G.; Morelli, M. A. C. Solution Structure of Human Calcitonin in Membrane-Mimetic Environment: The Roll of the Amphipathic Helix. Proteins 1998, 32, 314-323.
19. Motta, A.; Pastore, A.; Goud, N. A.; Morelli, M. A. C. Solution Conformation of Salmon Calcitonin in Sodium Dodecyl Sulfate Micelles as Determined by Two-Dimensional NMR and Distance Geometry Calculations. Biochemistry 1991, 30, $10444-$ 10450.

20. Copp, D. H. Endocrine Regulation of Calcium Metabolism. Annu. Rev. physiol. 1970, 32, 61-86. 